\title{
The New Probiotic Lactobacillus Plantarum Strain Isolated from Traditional Dairy Showed The Synergistic Effect on Aflatoxin B1 Detoxification Along with Nanochitosan Particles
}

\author{
Neda Zamani \\ Islamic Azad University Tehran North Branch \\ Abbas Akhavan Sepahi ( $\sim$ Akhavansepahy@gmail.com ) \\ Islamic Azad University Tehran North Branch https://orcid.org/0000-0002-4112-8962 \\ Mohammad Reza Fazeli \\ Tehran University of Medical Sciences Pharmaceutical Sciences Research Center \\ Farid Shariatmadari \\ Tarbiat Modares University Faculty of Medical Sciences
}

\section{Research Article}

Keywords: Aflatoxin B1, Probiotic, Lactobacillus plantarum, Nanochitosan

Posted Date: October 29th, 2021

DOI: https://doi.org/10.21203/rs.3.rs-1020223/v1

License: (c) (i) This work is licensed under a Creative Commons Attribution 4.0 International License. Read Full License 


\section{Abstract}

Background: Reduction of aflatoxin toxins in food products is of great importance. Therefore, in the present study, the effects of new Lactobacillus plantarum strain isolated from dairy products as well as chitosan nanoparticles were studied on reducing of aflatoxin B1 (AFB1) toxicity in vitro.

Methods: After collection and preparation yogurt, cheese, milk and whey products, lactic acid bacteria (LABs) were isolated and identified using biochemical and molecular methods. To measure probiotic activity, pH, bile and salt tolerance tests were used. Then, the antimicrobial activity of LABs against gastrointestinal pathogens was studied. Next, the cheese-separated strain (C1) was selected as the superior strain and antibiotic susceptibility testing was performed. Then, the effect of $\mathrm{C} 1$ isolate and chitosan nanoparticles on reducing aflatoxin B1 (AFB1) in the medium was studied by measuring AFB1 using the enzyme-linked immunosorbent assay (ELISA) and high performance liquid chromatography (HPLC).

Results: The results of biochemical evaluations indicated the separation of different strains of Lactobacillus plantarum. Antimicrobial activity test showed extensive antimicrobial activity of $\mathrm{C} 1$ isolate. The results showed that this strain has good probiotic activities. This strain was shown to be resistant to the antibiotics erythromycin, fusidic acid, gentamicin, kanamycin, nalidixic acid, neomycin, ofloxacin and vancomycin. $\mathrm{C} 1$ strain together with chitosan nanoparticles had the ability to reduce AFB1 in the medium and when both were used simultaneously, and synergistic effect in reducing AFB1 from the medium was seen.

Conclusion: In general, it was concluded that the new C1 L. plantarum strains together with chitosan nanoparticles could have synergistic effects in reducing AFB1 toxin in food products.

\section{Introduction}

Aflatoxins as the strongest mycotoxins (Man et al., 2017) are secondary metabolites produced by the fungal species including Aspergillus nomius, Aspergillus flavus, Aspergillus parasiticus (Gizachew et al., 2019). There are four type of aflatoxins (B1, B2, G1 and G2) that are carcinogenic to both humans and animals, among them, B1 is the most potent hepatotoxic and hepatocarcinogenic aflatoxin (Ostry et al., 2017). Aflatoxin B1 (AFB1) is very common in Southeast Asia and sub-Saharan Africa (Hamid et al., 2013).

Strategies to reduce aflatoxin contamination are based on the use of chemicals, which pose a risk of environmental pollution (Mohammed et al., 2018). Therefore, in recent years, other alternative methods have been considered, which include the use of microorganisms and plant essential oils in controlling the growth of aflatoxin-producing fungi (Gomez et al., 2018, Intanoo et al., 2018). The use of lactic acid bacteria (LABs) is the one of the strategies of aflatoxin removal from products. Numerous researchers have shown that some species of lactic acid bacteria and Bifidobacteria isolated from dairy can be effective in reducing aflatoxin contaminations (Istiqomah et al., 2017, Ibitoye et al., 2020).

Chitosan is a copolymer of glucosamine and $\mathrm{N}$-acetylglucosamine, which is produced by the $\mathrm{N}$-deacetylation of chitin and is a colorless, odorless substance whose good properties include non-toxicity, biodegradability, and biocompatibility (Wei et al., 2020). In recent years, the application of chitosan nanoparticles has attracted much attention due to its antimicrobial activity in the food and pharmaceutical industries (Perinelli et al., 2018). The antimicrobial properties of chitosan nanoparticles have been attributed to the interaction of the positively charged chitosan free group with the cell wall anions of microorganisms that alter cell wall permeability (Ma et al., 2017). It has also been reported that chitosan nanoparticles can cause resistance to microbial infections by increasing the accumulation of macrophages and activating them and inducing cytokines secretion (Rashki et al., 2020). The use of chitosan nanoparticles in microbial control is an environmentally friendly approach that reduces fungal infections.

Therefore, due to environmental and health concerns of fungicides usage thay can indirectly affect human health, so it is necessary to study approaches to reduce the mycotoxins in food products. Therefore, the present study was aimed to isolate probiotic Lactobacillus bacteria from traditional Iranian dairy products for investigating their aflatoxin B1 detoxification potentials and study their synergistic effects with chitosan nanoparticles in removing aflatoxin B1 in vitro. Isolated probiotic bacteria along with chitosan nanoparticles can be added to livestock and poultry feed as a binder toxin.

\section{Materials And Methods}




\section{Sample collection}

Ten Yogurt, five cheese, eight milk and five whey products of Iranian traditional dairy from Shiraz villages products were used to separate lactic acid bacteria and random sampling was performed according to the method (Hoque et al., 2010). We isolate 24 strains, among them 6 strains were selected for further study.

\section{Isolation of lactic acid bacteria from samples}

Separation of lactic acid bacteria ( $L A B)$ from the samples was performed according to recentenly reported method by Vanniyasingam et al. (2019). Briefly, $1 \mathrm{gr}$ samples was taken and they were serially diluted to $10^{-5}$ and spread on de Man, Rogosa and Sharpe (MRS) medium after homogenization. MRS medium contains $0.4 \%$ yeast extract $2.0 \%$ glucose $0.5 \%$ sodium acetate trihydrate and $0.1 \%$ polysorbate 80 . The petri dishes were then placed at $37{ }^{\circ} \mathrm{C}$ for two days in anaerobic conditions (5\% CO2) , after which $L A B$ colonies were removed from the medium and streaked on MRS agar medium to increase purity. Then, the produced LAB colonies were kept at $-20^{\circ} \mathrm{C}$ in broth containing $18 \%$ glycerol for further studies.

\section{Identification of bacteria}

To identify bacteria, Gram staining, morphology, Indole test for observation of SH2 production and tryptophan decomposition, catalase, $\mathrm{CO} 2$ gas production, staining of spores with malachite green dye, fermentation of different carbohydrates, and Simmon Citrate differential tests were used (Temmerman et al., 2004).

Fermentation test of different carbohydrates was done in MRS medium with $1 \%$ final sugar concentration and reagent of bromothymol blue and yeast and peptone extracts (arabinose, inositol, trehalose, raffinose, rhamnose, ribose, xylose, sucrose, cellobiose, fructose, glucose, lactose, mannose, mannitol, melibiose, melositosis) (Chen et al., 2005).

\section{Activation of selected bacteria}

MRS broth was used to incubate the isolated lactic acid bacteria at $30^{\circ} \mathrm{C}$ for 18 hours. After 18 hours, the number of bacteria was examined and they were cultured in brain-heart infusion agar slants (Oxoid, CM 1136) and stored at $4{ }^{\circ} \mathrm{C}$ (Yang and Chang, 2010).

\section{Evaluation of probiotic activites of isolated lactic acid bacteria}

\section{$\mathrm{pH}$ tolerance test}

To perform this test, The selected LAB isolate was cultured in MRS broth culture medium with different pHs from 1, 2, 3, 4, 5, 6, 7, 8 and 9 ( $\mathrm{pH}$ adjusted by $\mathrm{HCl}$ and $5 \% \mathrm{NaOH})$ and incubated at $37^{\circ} \mathrm{C}$ for $72 \mathrm{hrs}$ in anaerobic conditions $(5 \% \mathrm{CO} 2)$. Then samples were taken separately from each $\mathrm{pH}$ and cultured on MRS agar $\left(37^{\circ} \mathrm{C}, 24 \mathrm{~h}\right)$ and the survival of the isolates was confirmed by colonies growth. Also the growth of LAB was measured with a spectrophotometer at wave length of $620 \mathrm{~nm}$ (Gotcheva et al., 2002).

\section{Bile tolerance test}

The selected LAB isolate was cultured in MRS broth supplemented with $0.1,0.3,0.6,0.9$ and $1.2 \%$ oxgall $(\mathrm{pH} 6)$ and incubated at 37 ${ }^{\circ} \mathrm{C}$ for $72 \mathrm{hrs}$ in anaerobic conditions ( $\left.5 \% \mathrm{CO} 2\right)$. The survival of each sample was confirmed by culturing and growing them on MRS $\operatorname{agar}\left(37^{\circ} \mathrm{C}, 24 \mathrm{~h}\right)$, moreover the growth of LAB was monitored using spectrophotometer.(Gotcheva et al., 2002).

\section{Salt $(\mathrm{NaCl})$ tolerance test}

The selected LAB isolate was cultured in MRS broth supplemented with 2.5, 4.5, 6.5 and $8.5 \% \mathrm{NaCl}$ and incubated at $37^{\circ} \mathrm{C}$ for 72 hrs in anaerobic conditions ( $5 \% \mathrm{CO} 2$ ). After that The survival of the isolates was confirmed by culture and colonies growth on MRS $\operatorname{agar}\left(37^{\circ} \mathrm{C}, 24 \mathrm{~h}\right)$ and the growth of LAB was measured with a spectrophotometer. (Gotcheva et al., 2002)

\section{Molecular identification}

Bacterial Deoxyribonucleic Acid (DNA) was isolated by DENAzist Bacterial DNA isolation kit (Denazist Asia,Co, Mashhad,Iran) following manufacture instructors. Briefly, $1 \mathrm{~mL}$ of bacterial culture medium was centrifuged at $18928 \mathrm{~g}$ for 2 min and the supernatant was separated. Nanodrops were used to measure the quantity and quality of extracted DNA (Thermo Fisher, Waltham, 
MA). Specific primers for amplification of 16S ribosomal RNA (16SrRNA) fragments included F-5 'ATTCATAGTCTAGTTGGAGGT3' and R-5'-CCTGAACTGAGAGAATATTTGA-3. Bacterial genome DNA amplification was performed using polymerase chain reaction (PCR). The temperature program used included the initial temperature of $94^{\circ} \mathrm{C}$ for $3 \mathrm{~min}$ for denaturation, which followed by 32 cycles included the $1 \mathrm{~min}$ denaturation phase at $94^{\circ} \mathrm{C}, 1 \mathrm{~min}$ the annealing phase at $58^{\circ} \mathrm{C}$ and 1 minutes extension phase at $72{ }^{\circ} \mathrm{C}$. PCR products were run on $1.5 \%$ gel electrophoresis.

\section{Antimicrobial activity of LAB against bacterial patogens}

The selected lactobacillus isolate was cultured in MRS medium and incubated at $37^{\circ} \mathrm{C}$ for $48 \mathrm{hrs}$. They were centrifuged at $1792 \mathrm{~g}$ for $10 \mathrm{~min}$ and the supernatant was filtered by a 0.22 micron filter. To evaluate the antimicrobial activity of LABs, agar well diffusion method was used against bacteria of the gastrointestinal tract such as Salmonella enterica serovar Heidelberg (SH), Listeria monocytogenes Scott A, Escherichia coli 0157:H7 and Proteus vulgaris TG 155. MRS culture of C1 strain was centrifuged for 7 min at $7000 \mathrm{~g}$ and then supernatant passed through a $0.22 \mu \mathrm{m}$ filter. MRS medium containing the studied pathogens was prepared at a final concentration of $10^{6} \mathrm{CFU} \mathrm{ml}^{-1}$. Wells with a diameter of $5 \mathrm{~mm}$ were drilled on the surface of agar and filled with $100 \mu \mathrm{l}$ of supernatant. The plates were placed at $5{ }^{\circ} \mathrm{C}$ for $2 \mathrm{hrs}$ and then incubated for 2 days at $37^{\circ} \mathrm{C}$. Absence or presence of inhibitory zones was recorded (Strompfová et al., 2004).

\section{Antibiotic susceptibility test}

All antibiotic were purchased from (Nasr Pharma, Co, Tehran, Iran). The susceptibility and resistance of isolated bacteria to erythromycin (ERI), fusidic acid (FUS), gentamicin (GEN), kanamycin (KAN), nalidixic acid (NA), neomycin (NEO), ofloxacin (OFX), vancomycin (VAN), cephalothin (CEP), clindamycin (CLI), chloramphenicol (CLO), cloxacillin (CLOXA), tetracycline (TET) and novobiocin (NB) antibiotics were also assessed by agar disk-diffusion method. The agar diffusion medium was prepared by pouring Muller-Hinton melted agar onto petri dishes. Then, $100 \mu$ of inoculum, approximately $10^{8} \mathrm{cells} \mathrm{ml}^{-1}$, was steaked on agar surface. The antibiotic discs were then placed on the surface of medium with sterile forceps and after $24 \mathrm{hrs}$ of incubation at $37^{\circ} \mathrm{C}$, the growth inhibition zone was measured around the discs (Gallant-Behm et al., 2005).

\section{AFB1 extraction and clean up methods}

\section{Preparation of the standard AFB1}

Aflatoxin B1 (code:A6636) purchased from (Sigma-Aldrich, Inc, Munich, Germany) was dissolved in benzene-acetonitrile organic solvent according to manufacture instructions. Phosphate buffer was used to dilute the sample. To remove the organic solvent, water bath was used at $80^{\circ} \mathrm{C}$ for 15 minutes (Fazeli et al., 2009). After that, HPLC was performed to evaluate the quality and quantity of AFB1.

\section{Extraction of AFB1 from Aspergillus flavus}

First, A. flavus (PTCC 5018) purchased from (Iranian Research Organization for Science and Technology (IROST), Co, Tehran, Iran) was cultured in Potato dextrose broth (PDB) medium in several flasks and incubated at $26^{\circ} \mathrm{C}$ for two weeks. In order to extract aflatoxin from PDB medium, the contents of each flask were first mixed uniformly. The contents of the flasks were then passed through a Whatman 42 paper filter (with a porosity of 2 to $3 \mu \mathrm{m}$ ). For every $100 \mathrm{ml}$ of filtered solution, $40 \mathrm{ml}$ of chloroform solvent was added and the resulting mixture was stirred in a decanter funnel for $20 \mathrm{~min}$. After $24 \mathrm{hrs}$, the lower phase containing chloroform solvent and aflatoxin was isolated. The solvent was separated by a rotary apparatus at $45^{\circ} \mathrm{C}$ under vacuum. The residue was dissolved in $10 \mathrm{ml}$ of High Performance Liquid Chromatography (HPLC) purity methanol solvent (Merck, Darmstadt, Germany) and passed through a $0.22 \mu \mathrm{m}$ nozzle filter. The concentrated sample was stored in a freezer at $-20^{\circ} \mathrm{C}$. Then (HPLC) was performed for qualitative identification and quantitative measurement of AFB1 (Mekawey, 2018).

\section{Determination of aflatoxin B1 by HPLC}

The reverse-phase high-performance liquid chromatography (HPLC) procedure used for the analysis of AFB1 residues in the samplesof the supernatant fluids was as described by Fazeli et al. (2009). The HPLC system (model 2695, Waters Alliance, Milford, MA) was fitted with a dual-series pump solvent delivery system. A model 474 programmable fluorescence detector (Waters Alliance) and an ODS Sphere $5 \mathrm{C}-18$ column $(4.6 \mathrm{~mm}$ by $25 \mathrm{~cm}$ by $5 \mu \mathrm{m})$ fitted a guard column. Water-acetonitrile-methanol (6:2:3 [vol/vol/ 
vol]) was used as the mobile phase, with a flow rate of $1.000 \pm 0.005 \mathrm{ml} \mathrm{min}^{-1}$. The assay was carried out at room temperature with an injection volume of $40 \mu \mathrm{l}$. The detection wavelengths for excitation and emission were set at 345 and $435 \mathrm{~nm}$, respectively. The retention time of AFB1 was approximately 8 min (Fazeli et al., 2009).

\section{In vitro study of the effect of LAB and nanochitosan on AFB1}

\section{Measurement of free and LAB attached aflatoxin B1}

C1 strain was cultured in MRS broth and after a maximum growth of 48 hours (a volume of the culture broth corresponding to approximately $4.5 \times 10^{9} \mathrm{CFU} \mathrm{ml}^{-1}$ ), the tubes containing the bacteria were centrifuged for 15 minutes at $1008 \mathrm{~g}$. $\mathrm{C} 1$ precipitate was washed 3 times each time with $5 \mathrm{ml}$ of phosphate buffer solution (PBS) and added to $5 \mathrm{ml}$ of standard and extracted aflatoxin B1 solution in separate vials. The concentration of standard aflatoxin B1 was $5 \mu \mathrm{g} \mathrm{kg}^{-1}$ and the concentration of extracted aflatoxin B1 was $0.5 \mu \mathrm{g} \mathrm{kg}^{-1}$. Then they were incubated for $48 \mathrm{hrs}$ at $37^{\circ} \mathrm{C}$. The supernatant $(200 \mu \mathrm{L})$ were collected at different time intervals $(0$, 24 and $48 \mathrm{hrs}$ ), then each centrifuged for 15 minutes at $1792 \mathrm{~g}$. Free aflatoxin was isolated for measurement. The samples were screened with the The enzyme-linked immunosorbent assay (ELISA) aflatoxin B1 kit (ELISA kit, ZellBio, Co, Berlin, Germany) and the optimal sample was analyzed by HPLC, and finally the amount of aflatoxin attached to the bacteria was calculated. Then the collected supernatant samples resuspended in remaining samples to continue incubation for studing the incubation time effects.

\section{Measurement of nanochitosan- attached aflatoxin B1}

Nanochitosan (particle size $40 \mathrm{~nm}$, medium molecular weight 75\%, deacetylated) was purchased from (Nano pooyesh yekta corporation.Tehran, Iran) The chitosan nanoparticles (the concentrations 1.5 - 2.5 - $4.5 \mathrm{mg} \mathrm{ml}^{-1}$ ) was dissolved in $1 \%$ acetic acid solution ( $\mathrm{pH}$ 5.5) and incubated for $24 \mathrm{hrs}$. After preparation, different dilutions of nanoparticles (diluted in the concentrations 0.15 , $0.25,0.45 \mathrm{mg} \mathrm{ml}^{-1}$ ) were added to $5 \mathrm{ml}$ of standard and extracted aflatoxin B1 solution (respectively with concentrations $1 \mu \mathrm{g} \mathrm{kg}^{-1}$ and $0.1 \mathrm{~g} \mathrm{~kg}^{-1}$ ) in separate vials. Then they were incubated for $48 \mathrm{hrs}$ at $37^{\circ} \mathrm{C}$. The samples were then collected at time intervals of 0,24 and 48hrs and then the samples were centrifuged at $1792 \mathrm{~g}$ for $15 \mathrm{~min}$ to measure free aflatoxin. Samples were screened with ELISA aflatoxin B1 kit and the optimal sample was analyzed by HPLC.

To evaluate the effect of $\mathrm{pH}$, the optimum concentration of chitosan nanoparticles (obtained in the previous step) was incubated in $5 \mathrm{ml}$ of standard and extracted aflatoxin B1 solution (respectively with concentrations $1 \mu \mathrm{g} \mathrm{kg}^{-1}$ and $0.1 \mu \mathrm{g} \mathrm{kg}^{-1}$ ) at pHs $5.5,7$ and 8 in separate vials at $37^{\circ} \mathrm{C}$ for $24 \mathrm{hrs}$. Then the sample was centrifuged at $1792 \mathrm{~g}$ for $15 \mathrm{~min}$ to measure the amount of aflatoxin B1 bound to HPLC chitosan nanoparticles and the percentage of adsorption efficiency was calculated.

\section{Measurement of the synergistic effect of LAB and chitosan nanoparticles in reducing the toxicity effectiveness of aflatoxin B1}

LAB was cultured in MRS broth medium and incubated for $48 \mathrm{hrs}\left(4.5 \times 10^{9} \mathrm{CFU} \mathrm{ml}{ }^{-1}\right)$. Then the medium centrifuged for 15 min at $1008 \mathrm{~g}$. Bacterial precipitate was added to $5 \mathrm{ml}$ of standard and extracted aflatoxin B1 solution after washing three times with $5 \mathrm{ml}$ of PBS. The concentration of standard aflatoxin B1 was $1 \mu \mathrm{g} \mathrm{kg}^{-1}$ and the concentration of extracted aflatoxin B1 was $0.1 \mu \mathrm{g} \mathrm{kg}{ }^{-1}$. Also, chitosan nanoparticles after the same preparation as the prior step (with the optimal concentration obtained in the previous step) were added to the solution and incubated for $24 \mathrm{hrs}$ (the optimal time obtained in the previous step) at $37^{\circ} \mathrm{C}$. Then centrifuged for $15 \mathrm{~min}$ at $1792 \mathrm{~g}$ and finally the percentage of aflatoxin bound to bacteria and chitosan nanoparticles was calculated by HPLC.

\section{Statistical analysis}

All in vitro assays were conducted in triplicate and data were expressed as means \pm SD. Experiments related to AFB1 detoxification were performed based on a completely randomized design in factorial format. SPSS software version 26 was used for data analysis. Tukey's Multiple Range Test was used to compare the means. $\mathrm{P}<0.05$ was considered as a significant level.

\section{Results}

\section{Isolation of lactic acid bacteria from dairy products}


In the present study, 6 bacterial cultures were isolated from milk, yogurt, cheese and curd after one day of incubation at $37^{\circ} \mathrm{C}$. Three isolates were isolated from milk (M1, M2 and M3), and three isolate from yogurt (Y1), cheese (C1) and whey (W1) (Figure 1).

\section{Biochemical Evaluations}

Bacteria were examined for Gram staining, morphology, catalase, oxidase, spore, urease, nitrate reduction, sulfide indole motility (SIM) and citrate tests. All bacteria were gram-positive, catalase negative, oxidase negative, negative spores, urease negative, nitrate reduction negative, SIM negative, citrate negative and non-motile. Bacteria grew in both aerobic and anaerobic conditions, so all bacteria were facultative anaerobes. These results are consistent with the general specifications of LABs and the results of biochemical evaluation of 6 isolates separated from different dairy products are given in Table 1.

Table 1

The biochemical evaluations of isolates from milk, cheese, whey and youghourt

\begin{tabular}{|c|c|c|c|c|c|c|c|c|c|c|c|}
\hline Isolate & $\begin{array}{l}\text { Gram } \\
\text { Reaction }\end{array}$ & Shape & Catalase & Oxidase & Spores & Urease & $\begin{array}{l}\text { Nitrate } \\
\text { Reduction }\end{array}$ & SIM & Citrate & $\begin{array}{l}\text { Aerobic } \\
\text { Growth }\end{array}$ & $\begin{array}{l}\text { Anaerobic } \\
\text { Growth }\end{array}$ \\
\hline M1 & + & Bacilli & - & - & - & - & - & - & - & + & + \\
\hline M2 & + & Bacilli & - & - & - & - & - & - & - & + & + \\
\hline M3 & + & Bacilli & - & - & - & - & - & - & - & + & + \\
\hline $\mathrm{C} 1$ & + & Bacilli & - & - & - & - & - & - & - & + & + \\
\hline W1 & + & Bacilli & - & - & - & - & - & - & - & + & + \\
\hline Y1 & + & Bacilli & - & - & - & - & - & - & - & + & + \\
\hline
\end{tabular}

Sugar fermentation test indicated that the isolated Lactobacillus strain is capable of fermenting the sugars including arabinose, trehalose, raffinose, ribose, xylose, sucrose, cellobiose, fructose, galactose, lactose, mannose, mannitol, melobiose and melositosis unless rhamnose and inositol.

\section{Investigation Of Probiotic Activities Of Selected Lab}

The growth results of Lactobacillus selected strains separated from different dairy products indicated that $\mathrm{C} 1$ strain has a high tolerance against a wide spectrum of $\mathrm{pH}$, so that from $\mathrm{pH} 2$ to $\mathrm{pH}$, this strain grew, indicating high tolerance to the acidic condition of the small intestine and the probiotic properties of this strain (Figure 2).

Among the strains, the $\mathrm{C} 1$ strain showed the best resistance to the different concentrations of bile and $\mathrm{NaCl}$. The results of the present study showed that $\mathrm{C} 1$ strain survived well in different bile concentrations from $0.1-1.2 \%$ during the 48-hour incubation period. The initial growth of the $\mathrm{C} 1$ isolate was slow for up to $6 \mathrm{hrs}$, but the exponential growth of the strain began 6 hrs after cultivation and continued for $48 \mathrm{hrs}$. The growth rate of strain $\mathrm{C} 1$ was then reduced, indicating the bile-tolerant of this strain (Figure 3a).

In the present study, $\mathrm{NaCl}$ tolerance test of the selected strains was conducted and the results showed good survival of $\mathrm{C} 1$ isolate at high concentration of $\mathrm{NaCl}$. However, when the salt concentration increased the other strains growth were severely retarded (Figure 3b).

The growth of isolated strains on MRS agar after exposure to the test conditions showed survive of lactic acid bacteria, also Presence of cell growth was confirmed in strain $\mathrm{C} 1$.

\section{Molecular Identification}


The selected LAB isolate (C1) was identified by PCR technique as Lactobacillus plantarum (Figure 4a). The blast of the 16S rRNA gene sequence of strain $\mathrm{C} 1$ in the NCBI database indicated $100 \%$ similarity with Lactobacillus plantarum strain ZT-Lpl.34.

\section{The Phylogenetic Tree}

The results of blasting the 16S rRNA gene sequence of C1 isolate with 6 other strains in NCBI database indicated $100 \%$ identity of selected C1 strain with ZT-Lpl.34 strain (Figure 4b).

The phylogenetic tree was drawn with the Mega 7 program.

\section{Antimicrobial Activity}

The identified LABs isolates were studied against gastrointestinal pathogens including Salmonella enterica, Listeria monocytogenes, Escherichia coli and Proteus vulgaris and the results showed that LABs isolated from different dairy products have variable antimicrobial activities. Isolate $\mathrm{C} 1$ showed antimicrobial activity on all pathogens, however, other strains showed antimicrobial activity against some pathogens and M3 strain showed the lowest antimicrobial activity (Table 2).

Table 2

The zones of growth inhibition of gastrointestinal pathogens by against isolated LABs

\begin{tabular}{|lllll|}
\hline Isolates & Salmonella enterica $\left(\mathrm{mm}^{*}\right)$ & Listeria monocytogenes $(\mathrm{mm})$ & Escherichia coli $(\mathrm{mm})$ & Proteus vulgaris $(\mathrm{mm})$ \\
\hline M1 & $8.35 \pm 0.41$ & $10.23 \pm 0.34$ & $\mathrm{ND} * *$ & $\mathrm{ND}$ \\
\hline M2 & $10.22 \pm 0.53$ & $\mathrm{ND}$ & $9.45 \pm 0.34$ & $\mathrm{ND}$ \\
\hline M3 & $11.42 \pm 0.55$ & $\mathrm{ND}$ & $\mathrm{ND}$ & $\mathrm{ND}$ \\
\hline C1 & $12.35 \pm 0.49$ & $13.45 \pm 0.38$ & $14.45 \pm 0.72$ & $9.35 \pm 0.28$ \\
\hline W1 & ND & $\mathrm{ND}$ & $7.98 \pm 0.23$ & $\mathrm{ND}$ \\
\hline Y1 & ND & $11.24 \pm 0.43$ & $7.98 \pm 0.29$ & $\mathrm{ND}$ \\
\hline * millimeter ** not-detected & & & \\
\hline
\end{tabular}

\section{Antibiotic Resistance Assay}

The isolated strains were tested against a wide range of antibiotics and the results showed that $\mathrm{C} 1$ strain was resistant to the erythromycin, fusidic acid, gentamicin, kanamycin, nalidixic acid, neomycin, ofloxacin and vancomycin antibiotics, but was sensitive to the cephalothin, clindamycin, chloramphenicol, cloxacillin, tetracycline and novobiocin antibiotics (Table 3, Figure 5). 
Table 3

The isolated LABs antibiotic resistance

\begin{tabular}{|llllllllllllllll}
\hline Isolates & ERI & FUS & GEN & KAN & NA & CEP & CLI & NEO & OFX & CLO & CLOXA & VAN & TET & NB \\
\hline M1 & R* & R & S** & R & R & S & R & S & S & S & ND*** & R & R & S \\
M2 & R & R & R & S & S & R & ND & R & R & R & S & S & S & R \\
\hline M3 & S & S & R & R & S & S & S & R & ND & S & R & S & S & R \\
C1 & R & R & R & R & R & S & S & R & R & S & S & R & S & S \\
W1 & R & S & R & S & S & R & R & ND & S & R & S & R & R & S \\
Y1 & S & S & S & R & R & S & S & S & R & R & R & S & R & R \\
\hline
\end{tabular}

Abbreviation: (ERI) - erythromycin, (FUS) - fusidic acid, (GEN) - gentamicin, (KAN) - kanamycin, (NA) - nalidixic acid, (CEP) cephalothin, (CLI) - clindamycin, (NEO) - neomycin, (OFX) - ofloxacin, (CLO) - chloramphenicol, (CLOXA) - cloxacillin, (VAN) vancomycin, (TET) - tetracycline, (NB) - novobiocin

* Resistant, ** Sensitive, *** not-detected

\section{Detoxifying Of Aflatoxin B1 By Lab And Nanochitosan}

The results of the present study indicated a positive effect of the selected Lactobacillus strain on the reduction of both standard and extracted AFB1 in the medium. The rate of AFB1 adsorption was high and the highest binding of standard and extracted AFB1 to the bacterial strain was observed within 24 hours (Figure 6a, b). Standard and extracted AFB1 contents reduced by $44 \%$ and $39.17 \%$, respectively, by selected Lactobacillus strain.

A decrease in the standard and extracted AFB1 content of the medium was observed with the application of chitosan nanoparticles at different concentrations. The maximum reduction of standard and extraced AFB1 was observed at a concentration of 0.25 and $2.5 \mathrm{mg} \mathrm{l}^{-1}$ over $24 \mathrm{hrs}$, respectively (reduction of $17 \%$ and $25.59 \%$ in the content of standard and extracted AFB1, respectively) (Figure 6c,d). Also, the best effect was observed at pH 7.

An important finding in the present study was that when the selected Lactobacillus strain was used in combination with nanochitosan, a sharp decrease in the content of both standard and extracted AFB1 (\tilde 69\%) was observed. In other words, synergistic effects in reducing AFB1 content were observed when using the selected Lactobacillus strain with nanochitosan (Figure $6 e, f)$.

\section{Discussion}

Today, food contamination with various types of toxin-producing fungi is one of the serious problems of the international community (Fakruddin et al., 2015). Among them, Aspergillus flavus is one of the most important toxicogenic molds, which has received a lot of attention due to its ability to cause allergic conidiums and aflatoxin B1 (Alshannaq et al., 2018). AFB1 accumulates in various part of body including liver, lung, kidney, immune, reproductive, nervous and digestive systems and can have carcinogenic effects (Fouad et al., 2019).

LABs have general Gram-positive, catalase-negative, oxidase-negative, optional anaerobic, and immobilized properties (Leroy and De Vuyst, 2004) that are identical to the biochemical properties observed in the present study. In the present study, using biochemical approaches, the isolated strains were identified as Lactobacillus sp. Also, the molecular approach and amplification of 16S rRNA gene was used to identify the strains and the results showed that the species is Lactobacillus plantarum. Molecular approach can be very important in identifying accurately bacterial strains.

One of the most important characteristics of Lactobacillus sp. as a probiotic is its antimicrobial properties (Alishahi et al., 2018), and in the present study, the antimicrobial properties of Lactobacillus strains isolated from various dairy products were studied against gastrointestinal pathogens including Salmonella enterica, Listeria monocytogenes, Escherichia coli and Proteus vulgaris and the results showed that the strain isolated from cheese (C1) had broad spectrum antimicrobial activities and reduced the 
growth of all four pathogens. The antimicrobial properties of Lactobacillus sp. have been reported in other studies (Prabhurajeshwar and Chandrakanth, 2019). These antimicrobial activities include the production of bacteriocins (antimicrobial agents) and the production of compounds that inhibit bacterial growth, modulate intestinal $\mathrm{pH}$, strengthen the immune system, block bacterial binding sites, compete for food uptake, and produce organic acids (Hassan et al., 2020). The bacteriocins isolated from Lactobacillus are low molecular weight proteins (2-10 kDa) that are also resistant to heat, acidic conditions and cold (Silva et al., 2018).Bacteriocins exert their inhibitory effect on pathogenic bacteria by different mechanisms, including retardation of DNA synthesis (Mohammadi et al., 2018). Resistances to bile salts, $\mathrm{NaCl}$ and $\mathrm{pH}$ are common methods of investigating probiotic activity (Ahmad et al., 2018). Bile is secreted from the human liver, so the resistance of probiotics to bile is one of their important characteristics. Therefore, an important criterion in measuring probiotic activity is bile salt tolerance (Xu et al., 2020). In the current study, the $\mathrm{C} 1$ isolate showed good resistance to oxgall bile salts and bacterial growth continued at different concentrations of bile salts. This can be attributed to the ability of the $\mathrm{C} 1$ isolate to reduce the detergent effects of bile salts. The results of the current research are in line with other researches in this field (Chauhan and Daru, 2016); Azat et al. 2016) reported the survival rate at $\mathrm{pH} 3$ as a suitable criterion for $\mathrm{pH}$ resistance of probiotic strains (Azat et al., 2016). Isolate $\mathrm{C} 1$ continued to grow over a wide range of $\mathrm{pH}$, indicating probiotic effects. This has been shown in another study that Lactobacillus strains are able to survive even at $\mathrm{pH} 1$ (Maragkoudakis et al., 2010). Therefore, isolate $\mathrm{C} 1$ was considered $\mathrm{pH}$ resistant in the present study. This can be attributed to the ability of $\mathrm{C} 1$ isolate to maintain intracellular $\mathrm{pH}$ and better function of cellular proteins and enzymes. $\mathrm{NaCl}$ is an important inhibitor of bacteria and LABs are highly sensitive to this substance, therefore, their salt resistance is one of the important evaluations in measuring probiotic activity. In current study, high salt concentration (6.5\%) retarded the growth of $\mathrm{C} 1$ isolate but the bacteria could continue to grow at $4.5 \% \mathrm{NaCl}$. These results indicate appropriate probiotic activity of $\mathrm{C} 1$ isolate.

To evaluate the safety of probiotics, LAB antibiotic susceptibility test was performed and the results showed that C1 isolate was sensitive to cephalothin, clindamycin, chloramphenicol, cloxacillin, tetracycline and novobiocin antibiotics. Resistance to a different range of antibiotics in probiotics has been reported in other studies (Shobharani and Agrawal, 2011, Tambekar and Bhutada, 2010), which can be attributed to differences in the source of LABs isolation and differences in strains.

In recent years, the use of microorganisms including Lactobacillus sp. to detoxify AFB1 has attracted a lot of attention (Kumara et al., 2020, Chlebicz and Śliżewska, 2020). In the present study, it was shown that the C1 isolate was able to bind to AFB1 and was able to reduce both standard and extracted from Aspergillus flavus AFB1. Lactobacillus species have been shown to be able to bind to AFB1 via hydrophobic bonding due to the presence of specific compounds such as peptidoglycans and polysaccharides in the cell wall (Tajik and Sayadi, 2020). However, there are differences in aflatoxin reduction among different strains of this genus that can be attributed to different combinations of teichoic acid and peptidoglycan content in them (Hernandez-Mendoza et al., 2009). In the present study, binding of AFB1 to $\mathrm{C} 1$ strain of Lactobacillus plantarum was occurred rapidly over a period of $12 \mathrm{hrs}$, which is in line with the findings of (Gratz et al. 2005) reported that binding of AFB1 to Lactobacillus sp. is a fast process (Gratz et al., 2005). Rapid binding of AFB1 to Lactobacillus species has been shown in other studies (Kumara et al., 2019).

In the present study, the positive effect of chitosan nanoparticles in reducing AFB1 was shown and a concentration of $2.5 \mathrm{mg} \mathrm{ml}^{-1}$ was chosen as the optimal concentration of nanoparticles. It seems that positively charged chitosan nanoparticles can react with AFB1 and reduce its concentration in the medium. The antifungal effects of chitosan nanoparticles have been reported in other studies and it has been shown that chitosan nanoparticles have a strong affinity for attachment to fungal cell walls (Gomez et al., 2018). The present study is the first study to investigate the effects of chitosan nanoparticles on the reduction of AFB1 toxin and the results indicate the appropriate effect of chitosan nanoparticles on the reduction of AFB1.

In the present study, for the first time, the effect of the combination of chitosan nanoparticles with $\mathrm{C} 1$ isolate on reducing the AFB1 concentration was studied and the results showed the synergistic effects of the combination of the two in reducing the concentration of AFB1 in the medium. It seems that $\mathrm{C} 1$ isolate due to the presence of peptidoglycans and oligosaccharides in the cell wall and chitosan nanoparticles due to having a positive charge increased the adsorption of AFB1 to their surface and therefore, greatly reduced the concentration of AFB1 in the medium. However, more research is needed in this area.

Reduction of AFB1 toxin, due to the harmful effects on health, in food products is so important. In this study, it was concluded that $\mathrm{C} 1$ isolate was able to adsorb AFB1 from the medium and the simultaneous application of $\mathrm{C} 1$ isolate with chitosan nanoparticles led to a sharp decrease in the concentration of AFB1 in the environment. It seems that chitosan nanoparticles together with $\mathrm{C} 1$ isolate have synergistic effects in reducing AFB1 toxin from the medium. 


\section{Declarations}

\section{Conflicts of Interest}

The authors declare no conflicts of interest.

\section{Data Availability}

All data generated or analyzed during this study are included in this published article [and its supplementary information files]. Raw sequence data on 16s RNA gene had been submitted to the NCBI Sequence Read Archive (SRA) with the accession number PRJNA730567 (https://www.ncbi.nlm.nih.gov/bioproject/PRJNA733782/).

\section{References}

1. Ahmad, A., Yap, W. B., Kofli, N. T. and Ghazali, A. R. (2018) Probiotic potentials of Lactobacillus plantarum isolated from fermented durian (Tempoyak), a Malaysian traditional condiment. Food Sci Nutr, 6, 1370-1377.

2. Alishahi, M., Tulaby Dezfuly, Z., Mohammadian, T. and Mesbah, M. (2018) Effects of Two Probiotics, Lactobacillus Plantarum and Lactobacillus Bulgaricus on Growth Performance and Intestinal Lactic Acid Bacteria of Cyprinus Carpio. Iran J Vet Med, 12, 207-218.

3. Alshannaq, A. F., Gibbons, J. G., Lee, M.-K., Han, K.-H., Hong, S.-B. and Yu, J.-H. (2018) Controlling aflatoxin contamination and propagation of Aspergillus flavus by a soy-fermenting Aspergillus oryzae strain. Sci Rep, 8, 1-14.

4. Azat, R., Liu, Y., Li, W., Kayir, A., Lin, D.-B., Zhou, W.-W. and Zheng, X.-D. (2016) Probiotic properties of lactic acid bacteria isolated from traditionally fermented Xinjiang cheese. J Zhejiang Univ Sci B, 17, 597-609.

5. Chauhan, P. B. and Daru, D. (2016) Isolation and characterization of Lactobacillus isolated from milk, curd, and fecal sample and assigning their probiotic values. Int J Pharm Bio Sci, 0975-6299.

6. Chen, Y. S., Yanagida, F. and Shinohara, T. (2005) Isolation and identification of lactic acid bacteria from soil using an enrichment procedure. Lett Appl Microbiol, 40, 195-200.

7. Chlebicz, A., and Slizewska, K. (2020) In vitro detoxification of aflatoxin B 1, deoxynivalenol, fumonisins, T-2 toxin and zearalenone by probiotic bacteria from genus Lactobacillus and Saccharomyces cerevisiae yeast. Probiotics \& Antimicro. Prot, 12, 289-301.

8. Fakruddin, M., Chowdhury, A., Hossain, M. N., and Ahmed, M. M. (2015) Characterization of aflatoxin producing Aspergillus flavus from food and feed samples. SpringerPlus, 4, 1-6.

9. Fazeli, M. R., Hajimohammadali, M., Moshkani, A., Samadi, N., Jamalifar, H., Khoshayand, M. R., Vaghari, E. and Pouragahi, S. (2009) Aflatoxin B1 binding capacity of autochthonous strains of lactic acid bacteria. J Food Protect, 72, 189-192.

10. Fouad, A. M., Ruan, D., El-Senousey, H. K., Chen, W., Jiang, S., and Zheng, C. (2019) Harmful effects and control strategies of aflatoxin b1 produced by Aspergillus flavus and Aspergillus parasiticus strains on poultry. Toxins, 11, 176.

11. Gallant-behm, C. L., Yin, H. Q., Liu, S., Heggers, J. P., Langford, R. E., Olson, M. E., Hart, D. A. and Burrell, R. E. (2005) Comparison of in vitro disc diffusion and time kill-kinetic assays for the evaluation of antimicrobial wound dressing efficacy. Wound Repair Regen, 13, 412-421.

12. Gizachew, D., Chang, C.-H., Szonyi, B., De La Torre, S., and Ting, W.t. E. (2019) Aflatoxin B1 (AFB1) production by Aspergillus flavus and Aspergillus parasiticus on ground Nyjer seeds: The effect of water activity and temperature. Int J Food Microbiol, 296, 8-13.

13. Gomez, J. V., Tarazona, A., Mateo-Castro, R., Gimeno-Adelantado, J. V., Jimenez, M., and Mateo, E. M. (2018) Selected plant essential oils and their main active components, a promising approach to inhibit aflatoxigenic fungi and aflatoxin production in food. Food Additives \& Contaminants: Part A, 35, 1581-1595.

14. Gotcheva, V., Hristozova, E., Hristozova, T., Guo, M., Roshkova, Z. and Angelov, A. (2002) Assessment of potential probiotic properties of lactic acid bacteria and yeast strains. Food Biotechnol, 16, 211-225.

15. Gratz, S., Mykkänen, H., and El-Nezami, H. (2005) Aflatoxin B1 binding by a mixture of Lactobacillus and Propionibacterium: in vitro versus ex vivo. J Food Protect, 68, 2470-2474. 
16. Hamid, A. S., Tesfamariam, I. G., Zhang, Y., and Zhang, Z. G. (2013) Aflatoxin B1-induced hepatocellular carcinoma in developing countries: Geographical distribution, mechanism of action and prevention. Oncol Lett, 5, 1087-1092.

17. Hassan, M. U., Nayab, H., Rehman, T. U., Williamson, M. P., Haq, K. U., Shafi, N., and Shafique, F. (2020) Characterisation of bacteriocins produced by Lactobacillus spp. isolated from the traditional Pakistani yoghurt and their antimicrobial activity against common foodborne pathogens. Biomed Res Int, 2020. 8281623.

18. Hernandez-Mendoza, A., Guzman-de-Peña, D., and Garcia, H. S. (2009) Key role of teichoic acids on aflatoxin B binding by probiotic bacteria. J App/ Microbiol, 107, 395-403.

19. Hoque, M., Akter, F., Hossain, K., Rahman, M., Billah, M., and Islam, K. (2010) Isolation, identification and analysis of probiotic properties of Lactobacillus spp. from selective regional yoghurts. World J Dairy Food Sci, 5, 39-46.

20. Ibitoye, O. A., Olaniyi, O. O., Ogidi, C. O., and Akinyele, B. J. (2020) Lactic acid bacteria bio-detoxified aflatoxins contaminated cereals, ameliorate toxicological effects and improve haemato-histological parameters in albino rats. Toxin Rev, 1-12.

21. Intanoo, M., Kongkeitkajorn, M., Pattarajinda, V., Bernard, J., Callaway, T., Suriyasathaporn, W., and Phasuk, Y. (2018) Isolation and screening of aflatoxin-detoxifying yeast and bacteria from ruminal fluids to reduce aflatoxin $\mathrm{B} 1$ contamination in dairy cattle feed. J App/ Microbiol, 125, 1603-1613.

22. Istiqomah, L., Damayanti, E., Julendra, H., Suryani, A. E., Sakti, A. A., and Anggraeni, A. S.(2017) Effect of methionine and lactic acid bacteria as aflatoxin binder on broiler performance. In AIP Conf Proc, 1854, 020017. AIP Publishing LLC.

23. Kumara, S. S., Bashisht, A., Venkateswaran, G., Hariprasad, P., and Gayathri, D. (2019) Characterization of novel Lactobacillus fermentum from curd samples of indigenous cows from Malnad region, Karnataka, for their aflatoxin B 1 binding and probiotic properties. Probiotics Antimicrob Proteins, 11, 1100-1109.

24. Kumara, S. S., Gayathri, D., Hariprasad, P., Venkateswaran, G., and Swamy, C. T. (2020) In vivo AFB1 detoxification by Lactobacillus fermentum LC5/a with chlorophyll and immunopotentiating activity in albino mice. Toxicon, 187, $214-222$.

25. Leroy, F., and De Vuyst, L. (2004) Lactic acid bacteria as functional starter cultures for the food fermentation industry. Trends Food Sci. Technol, 15, 67-78.

26. Ma, Z., Garrido-Maestu, A., and Jeong, K. C. (2017) Application, mode of action, and in vivo activity of chitosan and its microand nanoparticles as antimicrobial agents: A review. Carbohydr Polym, 176, 257-265.

27. Man, Y., Liang, G., Li, A., and Pan, L. (2017) Recent advances in mycotoxin determination for food monitoring via microchip. Toxins, 9, 324.

28. Maragkoudakis, P. A., Chingwaru, W., Gradisnik, L., Tsakalidou, E., and Cencic, A. (2010) Lactic acid bacteria efficiently protect human and animal intestinal epithelial and immune cells from enteric virus infection. Int. J. Food Microbiol, 141, S91-S97.

29. Mekawey, A. A. I. (2018). (2018) Effects of Chitosan nanoparticles as antimicrobial activity and on mycotoxin production. Acad. J. Agric. Res, 6(5): 101-106.

30. Mohammadi, F., Eshaghi, M., Razavi, S., Sarokhalil, D. D., Talebi, M., and Pourshafie, M. R. (2018) Characterization of bacteriocin production in Lactobacillus spp. isolated from mother's milk. Microb Pathog, 118, 242-246.

31. Mohammed, A., Chala, A., Ojiewo, C., Dejene, M., Fininsa, Ch., Ayalew,A,. Hoisington, D.,Sobolev,V.. and Arias, R. (2018) Integrated management of Aspergillus species and aflatoxin production in groundnut (Arachis hypogaea L.) through application of farm yard manure and seed treatments with fungicides and Trichoderma species. Afr. J. Plant Sci, 12, 196-207.

32. Ostry, V., Malir, F., Toman, J., and Grosse, Y. (2017) Mycotoxins as human carcinogens-the IARC Monographs classification. Mycotoxin res, 33, 65-73.

33. Perinelli, D. R., Fagioli, L., Campana, R., Lam, J. K., Baffone, W., Palmieri, G. F., Casettari, L. and Bonacucina, G. (2018) Chitosanbased nanosystems and their exploited antimicrobial activity. Eur. J. Pharm. Sci, 117, 8-20.

34. Prabhurajeshwar, C., and Chandrakanth, K. (2019) Evaluation of antimicrobial properties and their substances against pathogenic bacteria in-vitro by probiotic Lactobacilli strains isolated from commercial yoghurt. Clin. Nutr. Exp, 23, 97-115.

35. Rashki, S., Asgarpour, K., Tarrahimofrad, H., Hashemipour, M., Ebrahimi, M. S., Fathizadeh, H., Khorshidi, A., Khan, H., SalavatiNiasari, M. and Mirzaei, H. (2020) Chitosan-based nanoparticles against bacterial infections. Carbohydr Polym, 117108.

36. Shobharani, P., and Agrawal, R. (2011) A potent probiotic strain from cheddar cheese. Indian J Microbiol, 51, 251-258.

37. Silva, C. C., Silva, S. P., and Ribeiro, S. C. (2018) Application of bacteriocins and protective cultures in dairy food preservation. Front Microbiol, 9, 594.

Page $11 / 16$ 
38. Strompfova, V., Laukova, A. and Ouwehand, A. C. (2004) Selection of enterococci for potential canine probiotic additives. Vet Microbiol, 100, 107-114.

39. Tajik, H., and Sayadi, M. (2020) Effects of probiotic bacteria of Lactobacillus acidophilus and Lactobacillus casei on aflatoxin B1 detoxification within a simulated gastrointestinal tract model. Toxin Revi, 1-8.

40. Tambekar, D., and Bhutada, S. (2010) An evaluation of probiotic potential of Lactobacillus sp. from milk of domestic animals and commercial available probiotic preparations in prevention of enteric bacterial infections. Recent res. sci. technol, 2, 82-88.

41. Temmerman, R., Huys, G. and Swings, J. (2004) Identification of lactic acid bacteria: culture-dependent and culture-independent methods. Trends Food Sci. Technol, 15, 348-359.

42. Vanniyasingam, J., Kapilan, R., and Vasantharuba, S. (2019) Isolation and characterization of potential probiotic lactic acid bacteria isolated from cow milk and milk products. AGRIEAST: j. Agric. Sci,13,32-43.

43. Wei, S., Ching, Y. C., and Chuah, C. H. (2020) Synthesis of chitosan aerogels as promising carriers for drug delivery: A review. Carbohydr Polym, 231, 115744.

44. Xu, Y., Zhou, T., Tang, H., Li, X., Chen, Y., Zhang, L., and Zhang, J. 2020. Probiotic potential and amylolytic properties of lactic acid bacteria isolated from Chinese fermented cereal foods. Food Control, 111, 107057.

45. Yang, E. and Chang, H. (2010) Purification of a new antifungal compound produced by Lactobacillus plantarum AF1 isolated from kimchi. Int J Food Microbial, 139, 56-63.

\section{Figures}
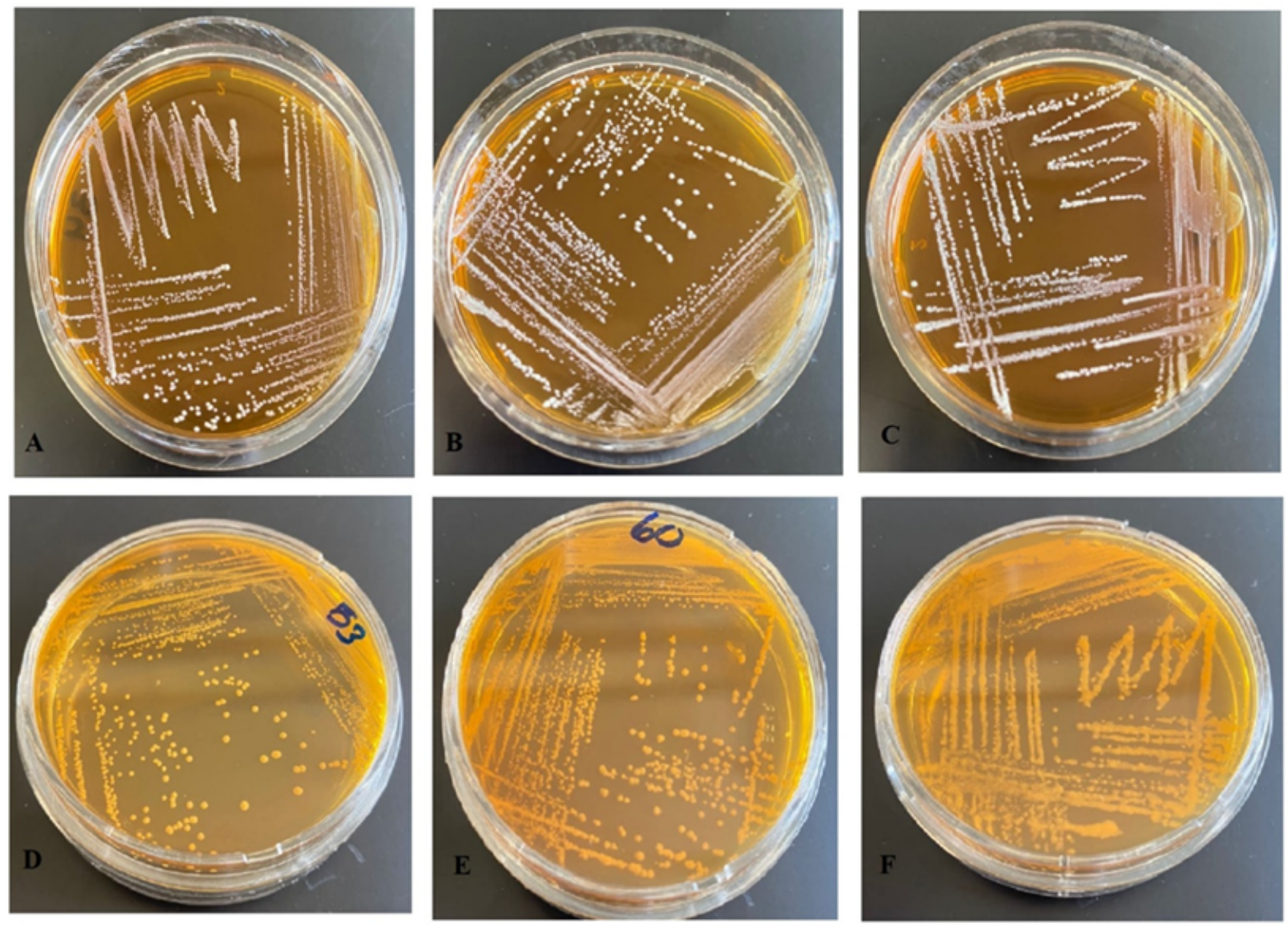

\section{Figure 1}

The lactic acids bacteria $(L A B)$ isolated from milk $(A, B, C)$, cheese, $(D)$, whey $(E)$ and yoghurt $(F)$ 


\section{$\mathrm{pH}$}

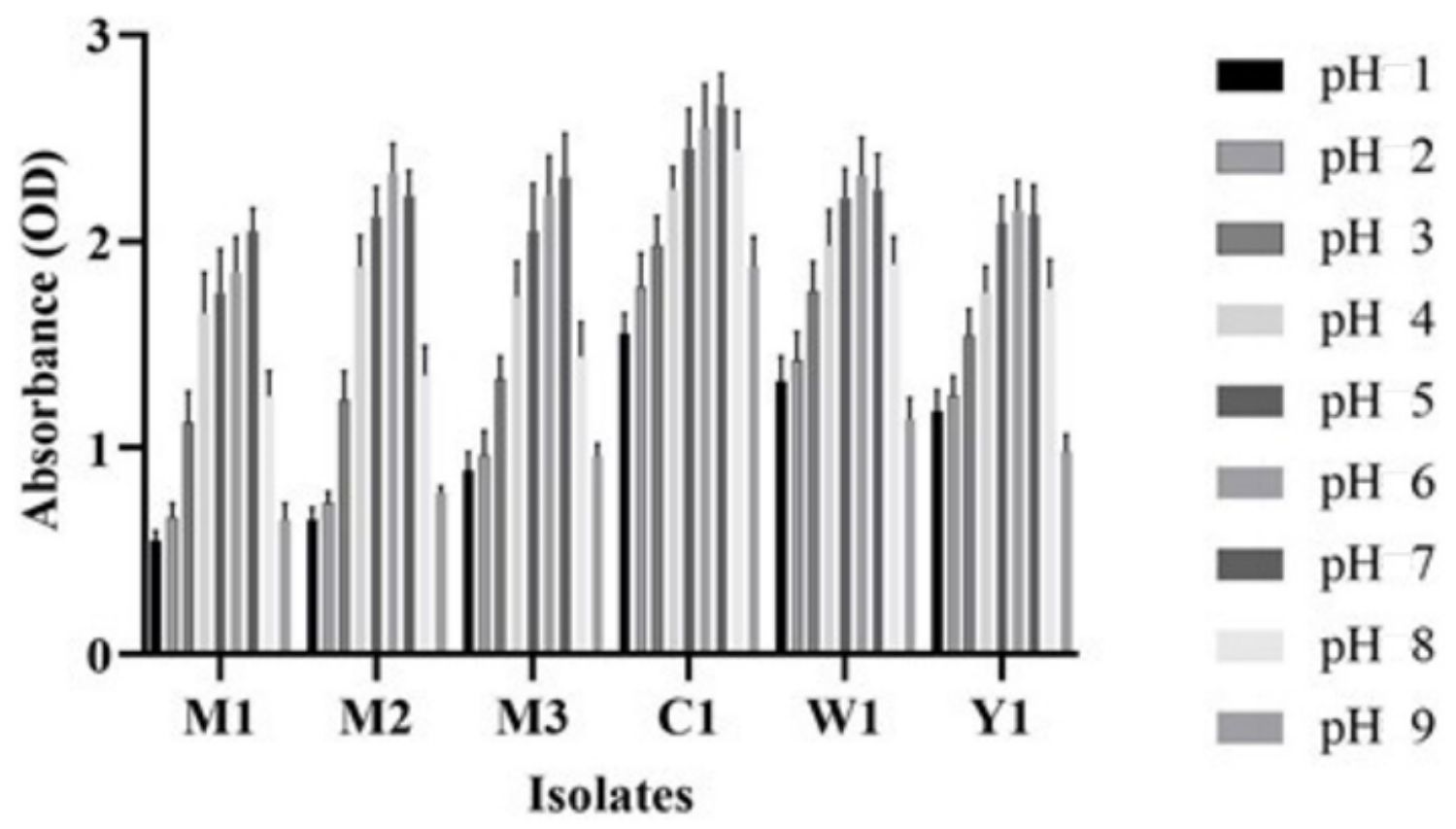

Figure 2

The effects of low (a) and high (b) $\mathrm{pH}$ on the growth of selected Lactobacillus isolates

$\mathbf{a}$

NaCl Tolerance

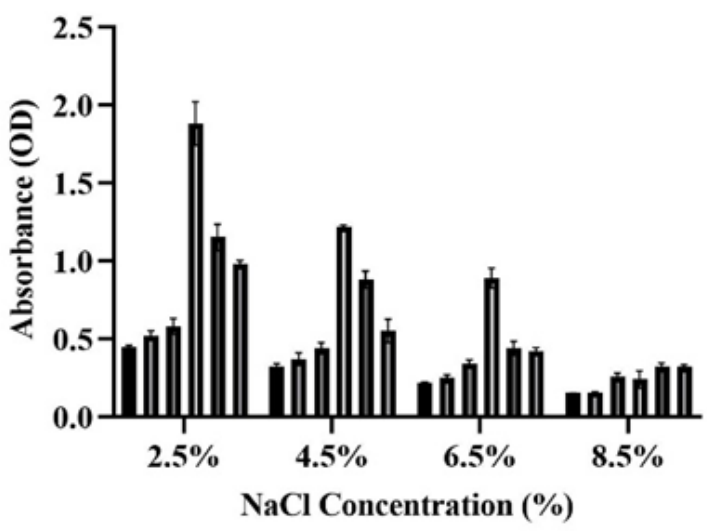

b

Bile Tolerance

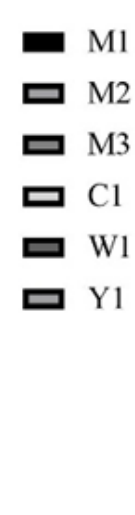

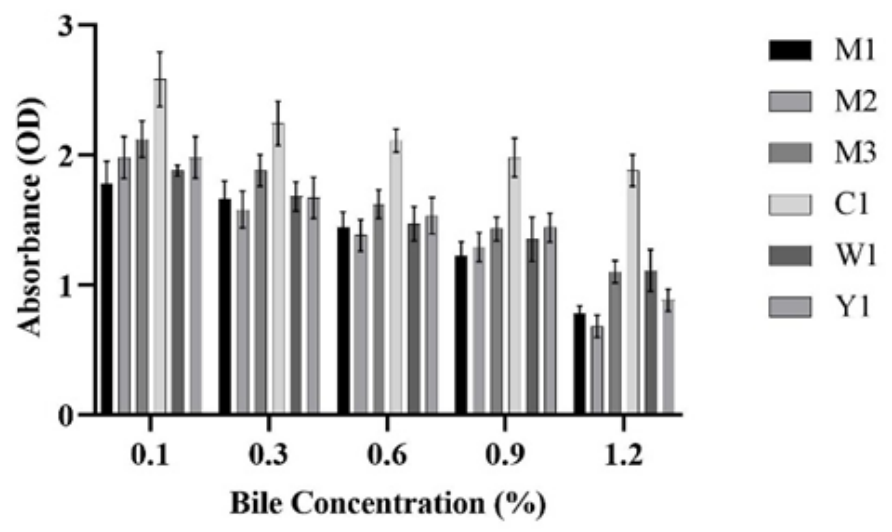

Figure 3

The effects of bile salt (a) and $\mathrm{NaCl}$ (b) on selected Lactobacillus isolate (C1) growth 


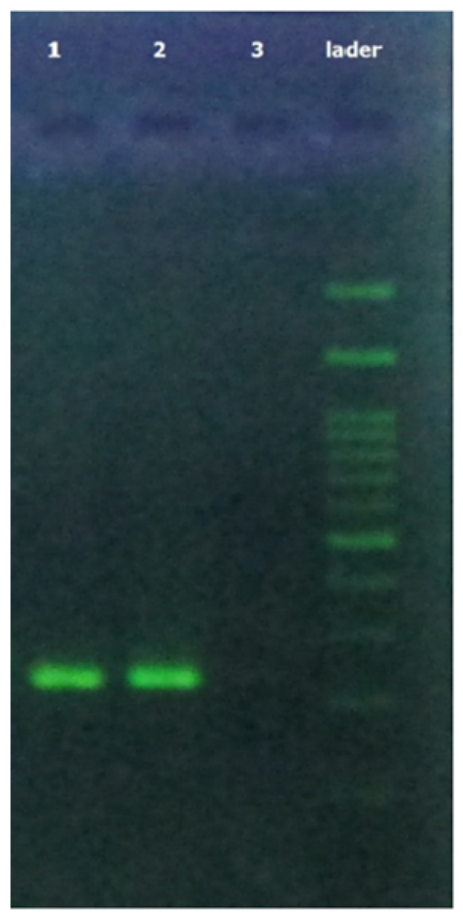

a

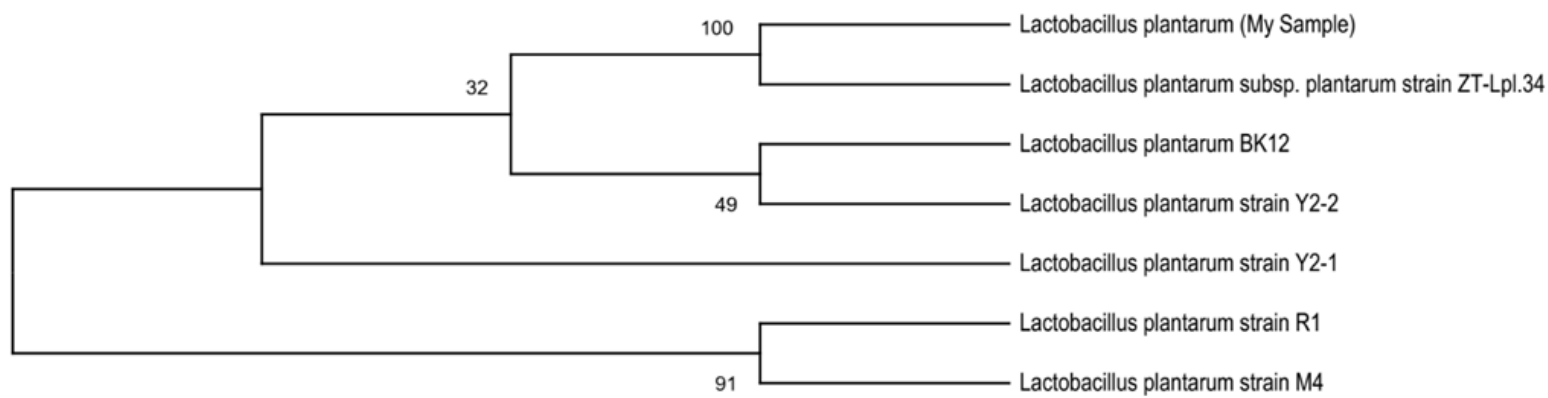

b

\section{Figure 4}

a The image of PCR products run on gel electrophoresis (1: plantarum(+), 2: sample, 3: negative control, M: Ladder 100 bp) b The blast of the 16S rRNA gene sequence with 6 strains sequence. The results of blast showed $100 \%$ identity of sequence with strain ZTLpl.34 


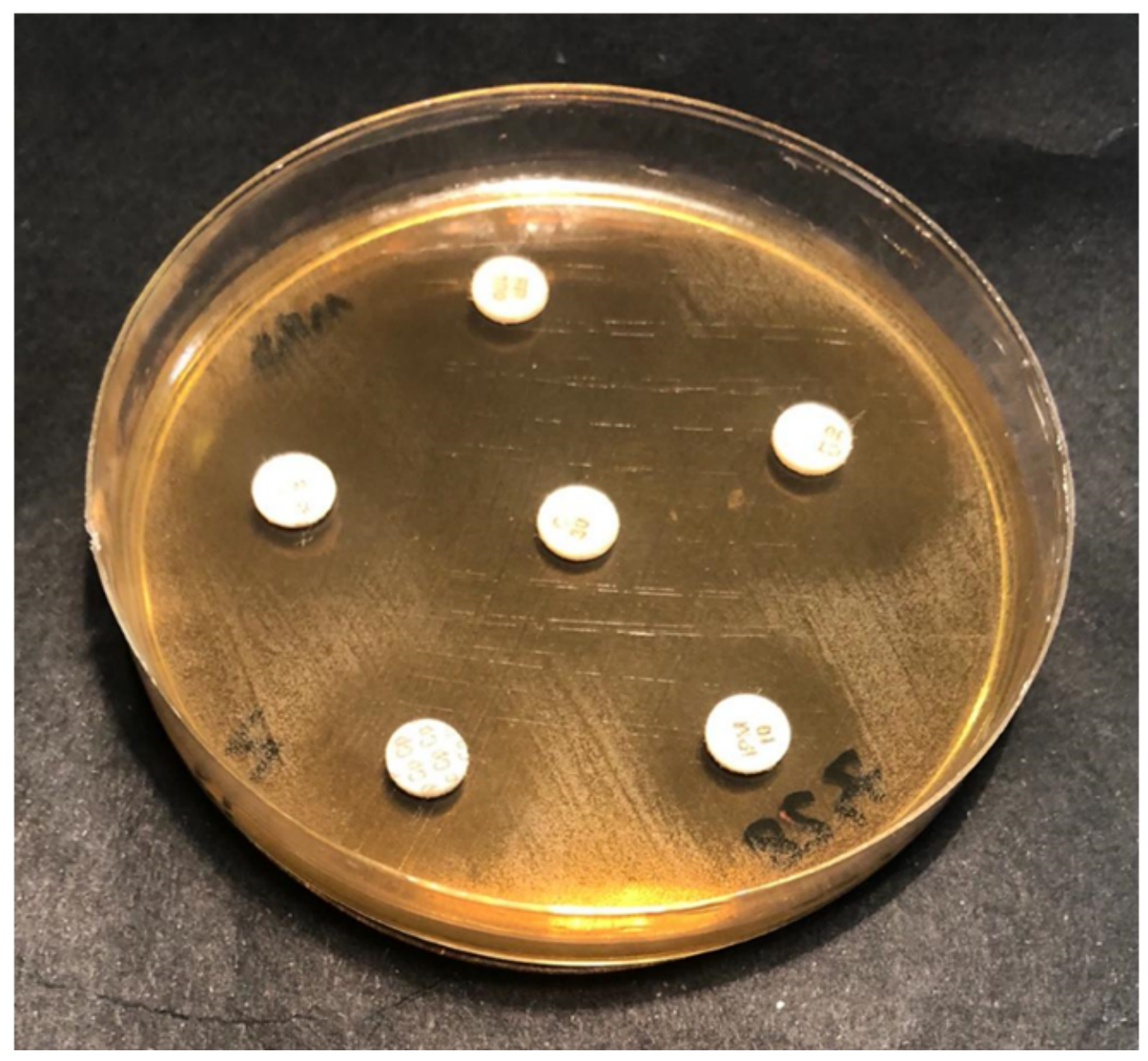

\section{Figure 5}

The evaluation of sensitivity of $\mathrm{C} 1$ isolate to the cephalothin (CEP), clindamycin (CD), chloramphenicol (C), cloxacillin (CLOXA), tetracycline (TE) and novobiocin (NB) antibiotics 
a

S-AFB1-LAB

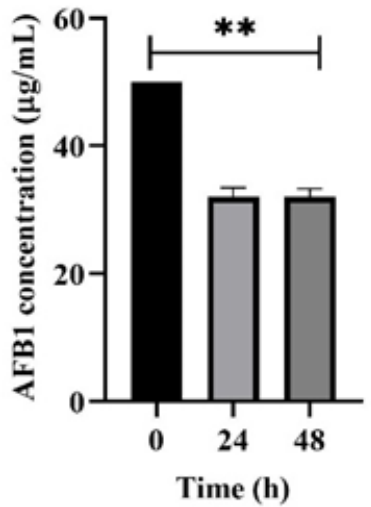

E-AFB1-LAB-NCh

d

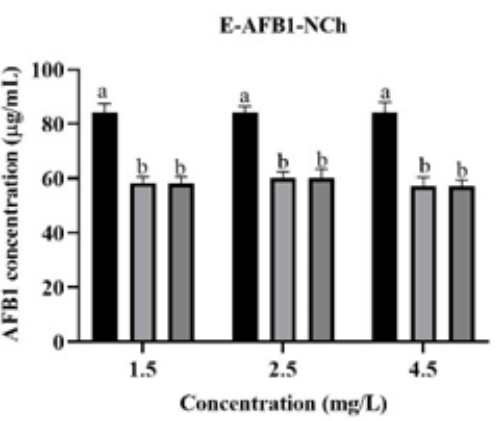

b

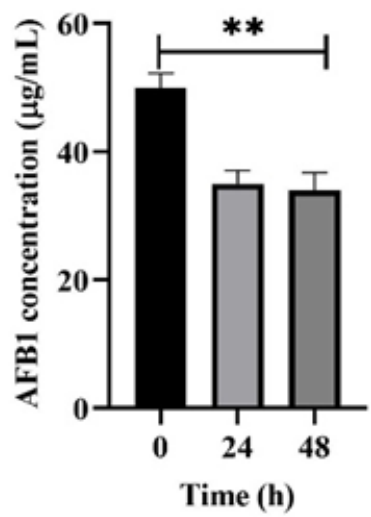

e

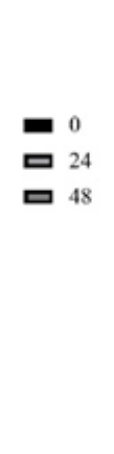

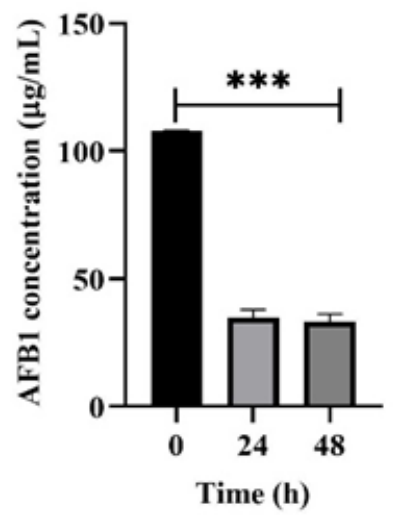

c

S-AFB1-NCh

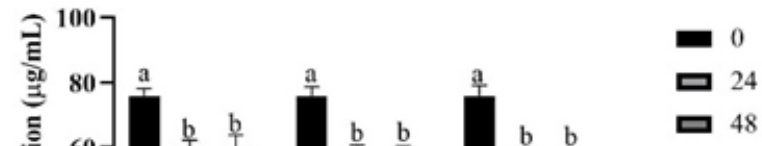

ㅁ 48

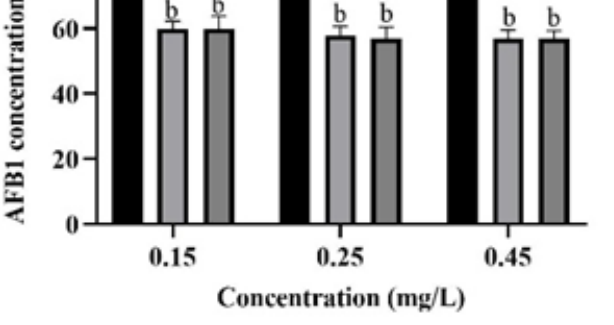

f

S-AFB1-LAB-NCh

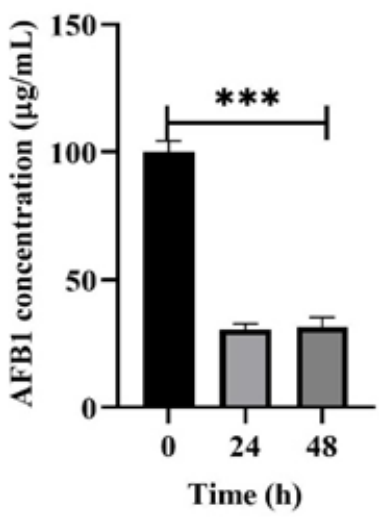

Figure 6

The effects of selected Lactobacillus plantarum strain $(a, b)$ and nanochitosan $(c, d)$ on standard and extracted AFB1 concentration in medium. e, f: the synergistic effects of selected Lactobacillus plantarum strain and nanochitosan on standard and extracted AFB1, respectively 